\title{
Corneal subepithelial monoclonal kappa IgG deposits in essential cryoglobulinaemia
}

\author{
ISRAEL KREMER,' PETER WRIGHT, ${ }^{2}$ SHAUL MERIN,${ }^{3}$ JEHUDA WEISS, \\ A I PICK, ${ }^{4}$ AND HERBERT KAUFMAN ${ }^{5}$
}

From the 'Departments of Ophthalmology and ${ }^{4}$ Clinical Immunology, Beilinson Medical Center, Petah Tiqva, and Tel Aviv University Sackler School of Medicine, Israel; the ${ }^{2}$ External Eye Diseases Clinic, Moorfields Eye Hospital, London; the ${ }^{3}$ Department of Ophthalmology, Hadassah Medical Center, Jerusalem, Israel; and ${ }^{5} L S U$ Eye Center, New Orleans, LA, USA

SUMMARY A 60-year-old man suffering from photophobia and visual disturbances was found to have bilateral superficial corneal grey-white gelatinous deposits. An abnormal cold-precipitable serum component was found and characterised as homogeneous IgG-kappa immunoglobulin. Corneal immunohistochemical examination revealed subepithelial IgG-kappa deposits, focally replacing Bowman's layer. The patient underwent superficial keratectomy in both eyes with satisfactory visual results.

Bilateral corneal deposits have been described in association with dysproteinaemia since $1934 .^{1-8}$ To our knowledge there is only one report ${ }^{9}$ describing corneal subepithelial immunoglobulin deposits in benign monoclonal gammopathy, simulating the clinical non-crystalline appearance and distribution of the corneal deposits found in our patient. Such deposits have never been described in essential cryoglobulinaemia. We present the results of bilateral superficial keratectomy performed on a patient with essential IgG-kappa cryoglobulinaemia, the only manifestation of which was the superficial corneal immunoglobulin deposits.

\section{Case report}

A 60-year-old man presented with photophobia, tearing, and gradually decreasing vision. On examination his best corrected visual acuity (VA) was $6 / 12$ in both eyes. Slit-lamp examination of both corneas showed raised gelatinous grey-white subepithelial avascular nodules, in the corneal periphery but sparing the limbus (Fig. 1). These confluent noncrystalline nodular masses extended towards the visual axis by finger-like projections. The corneal stroma, Descemet's membrane, and endothelium appeared normal. The anterior and posterior seg-

Correspondence to Dr I Kremer, Department of Ophthalmology, Beilinson Medical Center, Petah Tiqva, 49 100, Israel. ments were completely normal, as were the eyelids and conjunctiva.

The physical examination and bone $\mathrm{x}$-rays showed nothing abnormal.

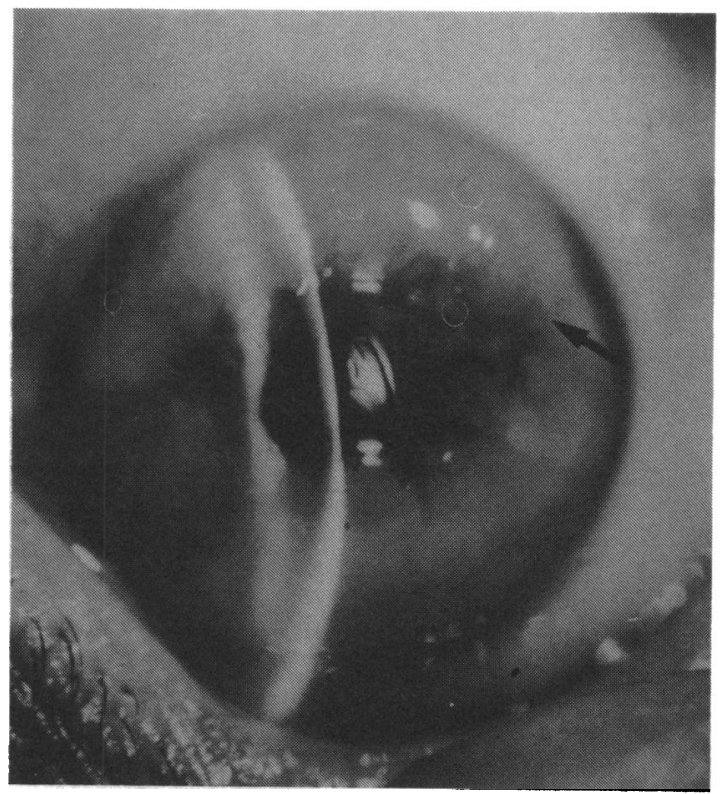

Fig. 1 Slit-lamp photograph showing the confluent nodular gelatinous-like superficial corneal deposits, extending towards the corneal centre by finger-like projections (arrow). 
Fig. 2 (a-d) Electrophoresis and immunoelectrophoresis of the patient's serum $(\mathrm{a}, \mathrm{b})$ and cryoprecipitate $(\mathrm{c}, \mathrm{d})$, revealing the presence of homogeneous $\operatorname{IgG-}$ kappa immunoglobulin.

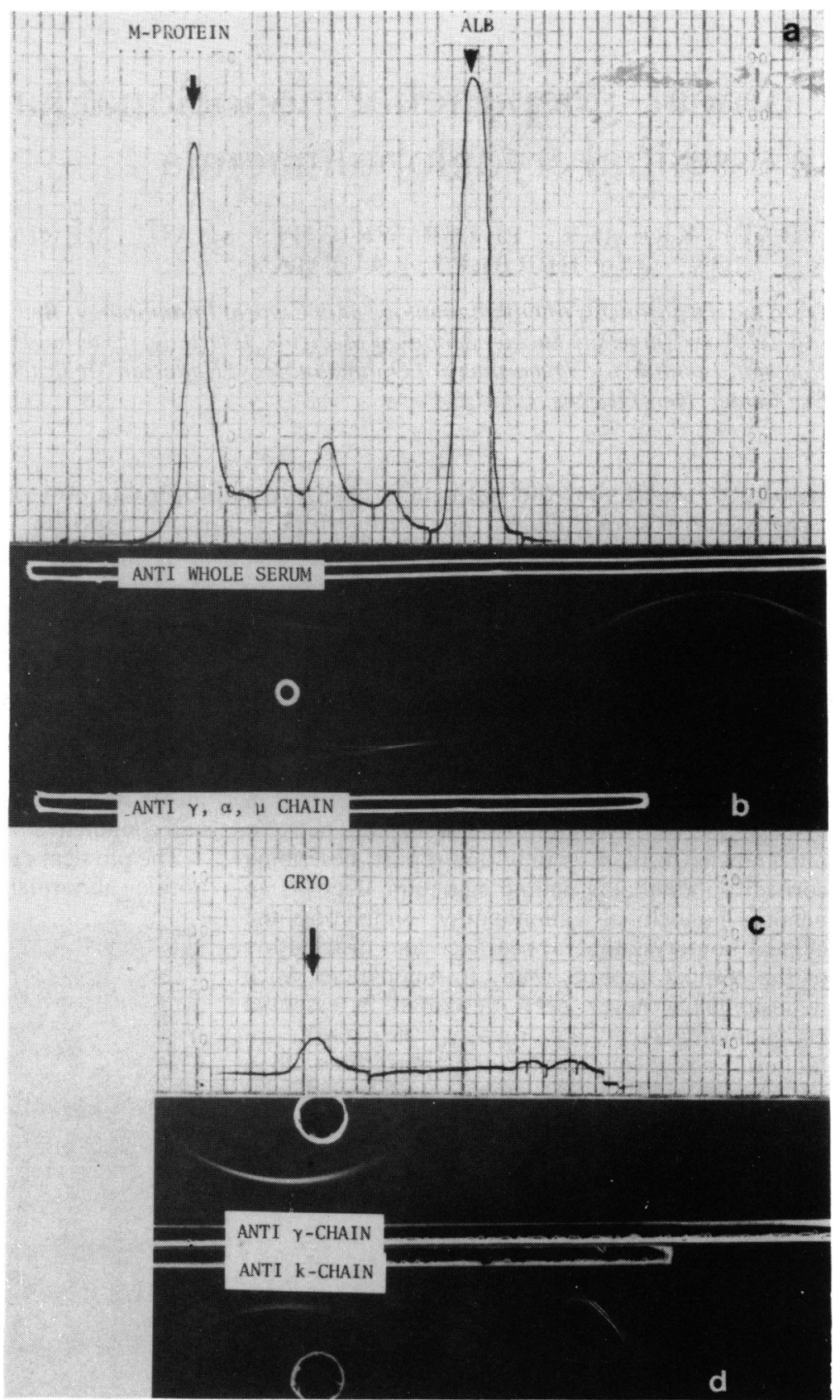

Subsequently the patient's serum was examined. A cryoprecipitate was discovered and was characterised by immunoelectrophoresis as a homogeneous IgG-kappa immunoglobulin (Fig. 2). Serum immunoglobulins were quantitated by nephelometry (Table 1).

Table 1 Results of serum cellulose acetate electrophoresis

\begin{tabular}{lll}
\hline Protein & $g / l$ & Normal range $g / l$ \\
\hline $\operatorname{lgG}$ & 30 & $2 \cdot(0-10 \cdot 5$ \\
$\operatorname{lgA}$ & $1 \cdot 86$ & $0 \cdot 8-2 \cdot 7$ \\
$\operatorname{lgM}$ & 1.24 & $0 \cdot 4-1 \cdot 1$
\end{tabular}




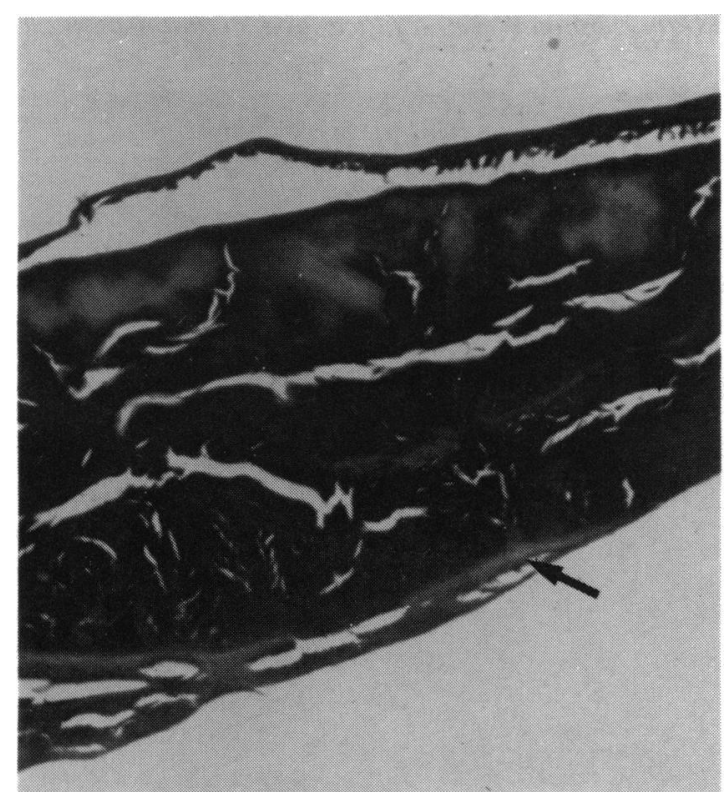

Fig. 3 Massive accumulation of red coloured subepithelial deposits located between the atrophic epithelium and Bowman's zone (arrow), which is focally disrupted. (Masson-trichrome stain, original magnification $\times 250$ ).
As a bone marrow biopsy showed normal appearances, the diagnosis of essential IgG-kappa cryoglobulinaemia was established.

A small lamellar biopsy was performed in the right cornea. The histopathological examination with haematoxylin-eosin showed eosinophilic subepithelial deposits, located between Bowman's layer or superficial stroma and basal epithelial layer. Bowman's layer was focally disrupted and replaced by the eosinophilic periodic acid Schiff positive material. With Masson trichrome staining redcoloured aggregates were seen beneath the elevated atrophic epithelium (Fig. 3). Stains for amyloid were negative. Electron microscopy revealed that the deposits were composed of numerous rod-shaped bodies (Fig. 4). Each rod was composed of parallel fine filaments with a $9 \cdot 5-10 \mathrm{~nm}$ periodicity (Fig. 5). A conjunctival biopsy revealed the presence of conjunctival subepithelial aggregates of homogeneous kappa-IgG (Fig. 6).

During the following years the VA decreased gradually to $6 / 40$, with J-7 in both eyes. It was not possible to perform skiascopy or keratometry, as the corneal surface was irregular.

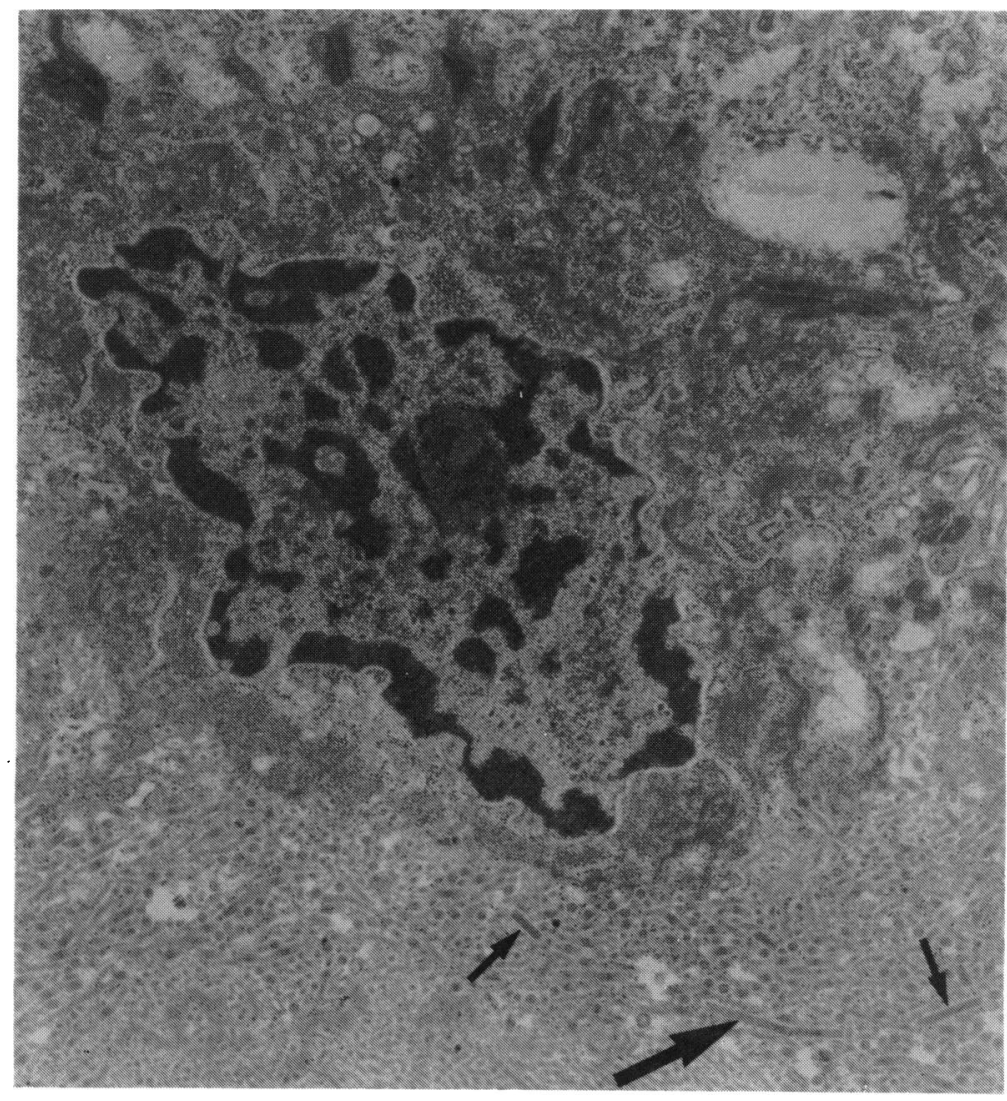

Fig. 4 Electron microscopy of the corneal biopsy specimen showing numerous subepithelial rod-shaped bodies (arrows). (Original magnification $\times 8200$.) 
Fig. 5 At higher magnification (EM) the rod-shaped bodies are seen to be composed of parallel fine filaments (arrow) with a periodicity of approximately $10 \mathrm{~nm}$. (Original magnification $\times 42000)$.

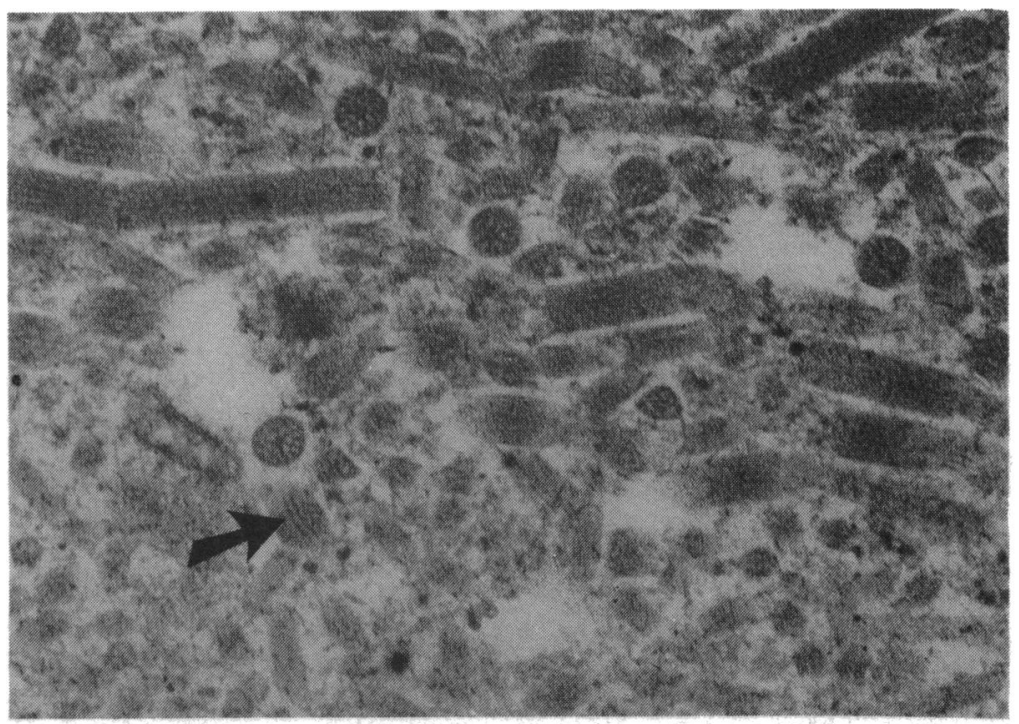

Owing to the subepithelial location of the corneal deposits, approaching the corneal centre, it was decided to perform superficial keratectomy by shaving the cornea with a scalpel blade. After this procedure, the VA improved to $6 / 7.5$ in the right eye and $6 / 7$ in the left, with J-1 in both eyes. The keratometry revealed bilateral regular astigmatism of $0.5 \mathrm{D}$.

Immunohistochemical examination of the keratectomised material showed that the corneal immunoglobulin deposits were antigenically identical to the homogeneous IgG-kappa (cryoglobulin) serum component.

Fourteen months after the operation the corneal surface was completely smooth, and a peripheral

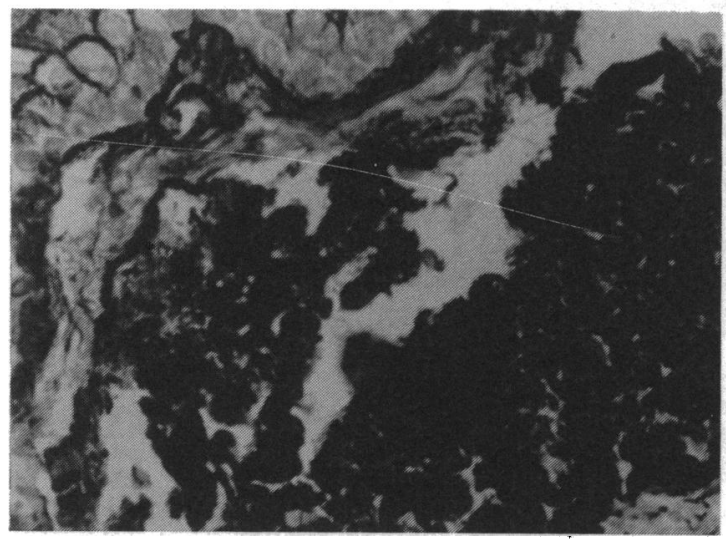

Fig. 6 Massive accumulation of conjunctival subepithelial immunoglobulin $G$ deposits (anti-IgG positive).

(Immunoperoxidase stain, original magnification $\times 400$.) band of superficial stromal scarring was noted bilaterally (Fig. 7).

\section{Discussion}

Corneal immunoglobulin deposits in association with hypergammaglobulinaemia have been described mainly as crystals..$^{4-10-14}$ The definitive evidence that the latter corneal crystals are immunoglobulins was provided by Klintworth et al. ${ }^{6}$ using immunofluorescent and immunoperoxidase techniques. Garner

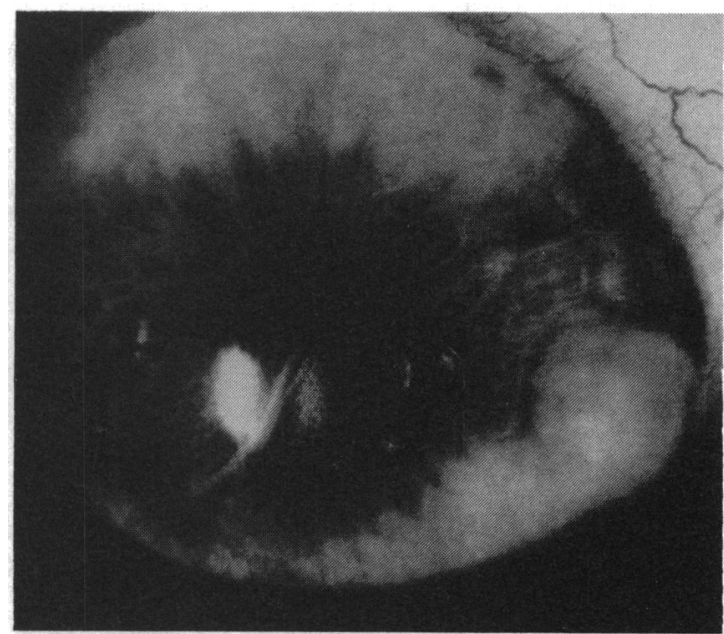

Fig. 7 Patient's right cornea six months after superficial keratectomy, showing confluent superficial stromal opacification covered by a completely smooth epithelium in those areas where the deposits have been removed. 
and Kirkness ${ }^{14}$ maintain that the unifying characteristic of these crystals is the $10 \mathrm{~nm}$ periodicity of their banded infrastructure.

The clinical appearance and anatomical location of these corneal deposits may be quite variable..$^{1314}$ In most cases they are found in the stroma ${ }^{2-5} 7-13$ and only rarely in the corneal epithelium proper ${ }^{6}$ or immediately beneath it. ${ }^{9}$ Paraproteinaemic keratopathy in association with true monoclonal gammopathy of unknown significance (MGUS) is very rare and has been reported in only four cases..$^{491315}$ Our patient is the fifth recorded case with MGUS. However, as the monoclonal paraprotein found in his serum had the characteristics of cryoglobulin his disease may be defined also as essential cryoglobulinaemia.

As regards cryoglobulinaemia, $\mathrm{Palm}^{15}$ was the first author to report on superficial corneal deposits in a case of crystalcryoglobulinaemia. The nature of these corneal deposits differed from that of our patient in that they had a crystalline appearance. Oglesby ${ }^{16}$ is the only author to report on corneal non-crystalline deposits in a patient with cryoglobulinaemia, which was associated with reticulohistiocytosis. The corneal stromal involvement in this patient was predominantly posterior. However, Oglesby ${ }^{16}$ presented no histological or immunohistochemical proof for the presence of corneal immunoglobulin deposits. No surgical or medical treatment was mentioned in these two reports. ${ }^{15} 16$

Allansmith and colleagues ${ }^{17}{ }^{18}$ reported that almost all immunoglobulins can be found in normal corneas and that their concentration correlates with the serum level. They maintain that corneal immunoglobulins are derived mainly from the serum by diffusion from perilimbal vessels.

The presence of a cold precipitable immunoglobulin in the serum of our patient may explain its massive preferential accumulation in the corneal subepithelial region, as it is probably one of the coldest areas in the human body. ${ }^{19}$ According to Waltman and Hart $^{19}$ the difference in temperature between the rabbit cornea and the iris amounts to $5^{\circ} \mathrm{C}$. As the cryoglobulin precipitates in a temperature below $34^{\circ} \mathrm{C}$, it may undergo crystalloid changes following precipitation under the corneal epithelium, the temperature of which is probably around $32^{\circ} \mathrm{C}$.

These corneal cryoglobulin precipitates found in our patient were removed by superficial keratectomy, after which a smooth corneal resurfacing was achieved. For the time being invasive surgical techniques, such as perforating or lamellar keratoplasty, have been postponed. Whenever the abovedescribed corneal deposits recur outside the corneal centre, superficial keratectomy can be repeated. However, if they appear in the central zone, keratoplasty is indicated. It is our opinion that this procedure should probably be supplemented in future either by plasmapheresis or by low dosage chemotherapy ${ }^{20}$ in order to keep the corneal graft clear.

\section{References}

1 Meesmann A. Über eine eigenartige Hornhautdegeneration (Ablagerung der Bence-Jonesschen Einweisskörper in der Hornhaut). Ber Dtsch Ophthalmol Ges 1934; 50: 311-5.

2 Burki E. Über Hornhautveranderung bei einen Fall von multiplem Myelom (Plasmocytom). Ophthalmologica 1958; 135: 565-72.

3 Miller KH, Green WR, Stark WJ, Wells HA, Mendelsohn G, Kanhofer H. Immunoprotein deposition in the cornea. Ophthalmology 1980; 87: 944-50.

4 Rodriques MM, Krachmer JH, Miller SD, Newsome DA. Posterior corneal crystalline deposits in benign monoclonal gammopathy: a clinicopathologic case report. Arch Ophthalmol 1979; 97: 124-8.

5 Aronson SB, Shaw R. Corneal crystals in multiple myeloma. Arch Ophthalmol 1959; 61: 541-6.

6 Klintworth GK, Bredehoeft SJ, Reed JW. Analysis of corneal crystalline deposits in multiple myeloma. Am J Ophthalmol 1978; 86: 303-13.

7 Barr CC, Geleder H, Font RL. Corneal crystalline deposits associated with dysproteinemia: report of two cases and review of the literature. Arch Ophthalmol 1980; 98: 884-9.

8 François J, Rabaey M. Corneal dystrophy and paraproteinemia. Am J Ophthalmol 1961; 52: 895-901.

9 Eiferman RA, Rodriques MM. Unusual superficial stromal corneal deposits in IgG K monoclonal gammopathy. Arch Ophthalmol 1980; 98: 78-81.

10 Laibson PR, Damiano VV. $X$-ray and electron diffraction of ocular and bone marrow crystals in paraproteinemia. Science 1969; 163: 581-3.

11 Pinkerton RMH, Robertson DM. Corneal and conjunctival changes in dysproteinemia. Invest Ophthalmol Vis Sci 1969; 8: 357-64.

12 François $\mathrm{J}$. Paraproteinaemic thesaurismosis of the cornea in Kahler's multiple myelomatosis. Eye Ear Nose Throat J 1967; 46: 857-67.

13 Ormerod LD, Collin HB, Dohlman CH, Graft JL. Desforges JF, Albert DM. Paraproteinemic crystalline keratopathy. Ophthalmology 1988; 95: 202-12.

14 Garner A, Kirkness CM. Corneal gammopathy. Cornea in press.

15 Palm E. A case of crystal deposits in the cornea. Precipitation of a spontaneously crystallizing plasma globulin. Acta Ophthalmol (Kbh) 1947; 25: 165-74.

16 Oglesby R. Corneal opacities in a patient with cryoglobulinemia and reticulohistiocytosis. Arch Ophthalmol 1961; 65: 63-6.

17 Allansmith MR, McClellan BH. Immunoglobulins in the human cornea. Am J Ophthalmol 1975; 80: 123-32.

18 Allansmith MR, Whitney CR, McClellan BH, Newman LP. Immunoglobulins in the human eye. Location, type, and amount. Arch Ophthalmol 1973; 89: 36-45.

19 Waltman SR, Hart Jr WM. The cornea. In: Moses RA, Hart Jr WM, eds. Adler's physiology of the eye-clinical application. 8th ed. St Louis: Mosby, 1987; chapter 3: 36-59.

20 Firkim FC, Lee N, Ramsey R, Robertson IS. Visual loss caused by corneal crystals in myeloma. Rapid improvement with plasma exchange and chemotherapy. Med J Aust 1979; ii: 677-8.

Accepted for publication 3 February 1989. 